\title{
Cene gozdnih lesnih sortimentov v drugi polovici leta 2021 rekordne
}

Špela Ščap, Gozdarski inštitut Slovenije, Oddelek za gozdno tehniko in ekonomiko Darja Stare, Gozdarski inštitut Slovenije, Oddelek za gozdno tehniko in ekonomiko

Objavljeno na spletu 19.01.2022 (https://doi.org/10.20315/IG.2022.0007)

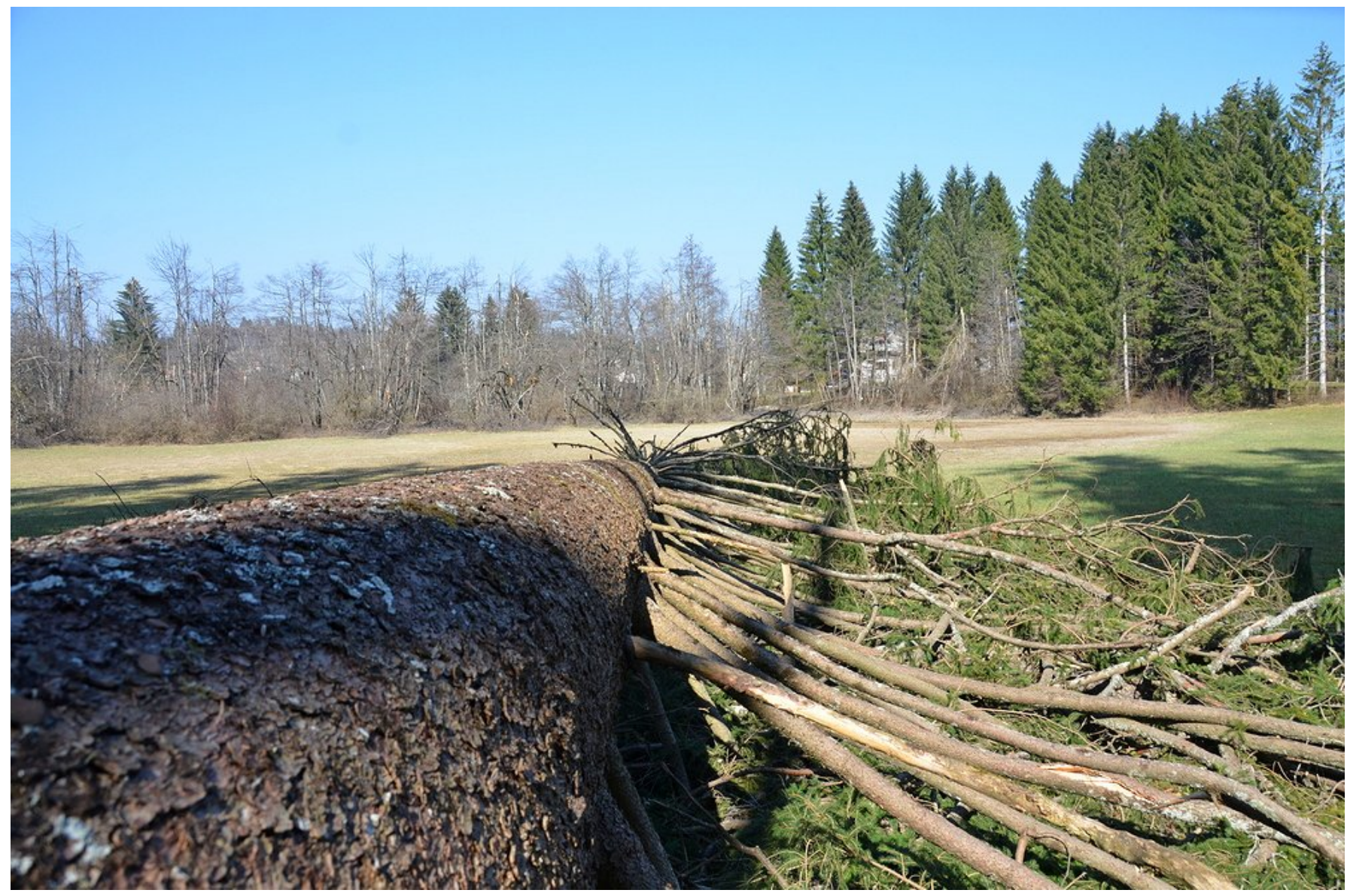

V lanskem letu smo na Gozdarskem inštitutu Slovenije spremljali odkupne cene gozdnih lesnih sortimentov ( $v$ nadaljevanju GLS) iz zasebnih gozdov vsako četrtletje, sicer pa cene za 38 različnih GLS spremljamo od leta 2017 naprej in jih javno objavljamo na spletnem portalu InfoGozd (WCM) v rubriki »Cene« ali še bolj podrobno v rubriki »Kazalniki gospodarjenja z gozdovi« ter tudi v obliki aktualnih novic. 


\section{Uvod}

Odkupne cene GLS iz zasebnih gozdov so bile v letu 2020 v veliki meri odraz predvsem posledic ukrepov Vlade RS za omejitev negativnih posledic epidemije bolezni SARS-CoV-2 za prebivalstvo in gospodarstvo ter za njegovo hitrejše okrevanje ter dogajanja na trgih lesa v Evropi in svetu. $V$ letu 2021 pa se je predvsem žagarska industrija soočala s pomanjkanjem hlodovine iglavcev na slovenskem trgu in širše, kar je privedlo do izrazitega porasta cen teh sortimentov. Glavni razlog za pomanjkanje industrijskega okroglega lesa iglavcev (tako hlodovine kot lesa slabše kakovosti) na trgu v letu 2021 je za več kot polovico manjši obseg sanitarne sečnje v slovenskih gozdovih kot v letu 2020.

\section{Največji porast cen lani pri hlodovini smreke in jelke}

Največji porast cen smo lani glede na leto 2020 zaznali pri hlodih smreke kakovostnega razreda C in sicer je srednja vrednost cen za ta sortiment v februarju, maju, avgustu in novembru (to so meseci v sredini obdobja vsakega četrtletja) leta 2020 znašala $65 € / m 3$ brez DDV, v enakih mesecih leta 2021 pa $92 € / m 3$ brez DDV, kar pomeni zvišanje cene za $27 € / m 3$ brez DDV.

Preglednica 1: Srednje vrednosti vseh zbranih odkupnih cen hlodovine smreke v vsakem četrtletju leta 2020 in 2021 (cene so prikazane $v € / m 3$ brez DDV na kamionski cesti)

\begin{tabular}{|c|c|c|}
\hline & $\begin{array}{c}\text { Srednja vrednost (mediana) } \\
\text { za obdobje februar, maj, } \\
\text { avgust, november } 2020\end{array}$ & $\begin{array}{c}\text { Srednja vrednost (mediana) } \\
\text { za obdobje februar, maj, } \\
\text { avgust, november } 2021\end{array}$ \\
\hline \multirow[b]{2}{*}{ Smreka A } & Cena $\left[€ / \mathrm{m}^{3}\right.$ brez DDV] & Cena $\left[€ / \mathrm{m}^{3}\right.$ brez DDV] \\
\hline & 100 & 120 \\
\hline Smreka B & 78 & 100 \\
\hline Smreka C & 65 & 92 \\
\hline Smreka D1 & 50 & 75 \\
\hline Smreka D2 & 40 & 61 \\
\hline
\end{tabular}

$\checkmark$ avgustu in novembru lanskega leta smo zaznali rekordne cene hlodovine iglavcev odkar na Gozdarskem inštitutu Slovenije spremljamo cene GLS. Odkupne cene hlodov smreke kakovostnih razredov D2 do A iz zasebnih gozdov so se v avgustu leta 2021 gibale med 70-140 €/m3 brez DDV, medtem ko so se cene $v$ enakem mesecu leta 2020 gibale med $40-100 € / \mathrm{m} 3$ brez DDV. Največji porast cen $v$ tem mesecu je bil pri smreki kakovostnega razreda $C(+85 \%)$. Podobno velja za november; lani so se cene hlodov smreke kakovostnih razredov D2 do A gibale med 70-130 €/m3 brez DDV, medtem ko so cene v novembru 2020 znašale od 43 do $100 € / \mathrm{m} 3$ brez DDV.

Cene so se v lanskem letu zvišale tudi pri hlodovini jelke in rdečega bora, vendar slednje ne tako izrazito kot pri smreki in jelki. Odkupne cene hlodov jelke kakovostnih razredov D2 do A iz zasebnih gozdov so se $v$ avgustu leta 2021 gibale med 70-117 €/m3 brez DDV, medtem ko so se cene $v$ enakem mesecu leta 2020 gibale med 40-70 €/m3 brez DDV. Največji porast cen je bil pri jelki kakovostnega razreda C (+85\%). Cene hlodov rdečega bora kakovostnih razredov D2 do A so se lani 
avgusta gibale med 50-90 €/m3 brez DDV, avgusta 2020 pa med 40-60€/m3 brez DDV.

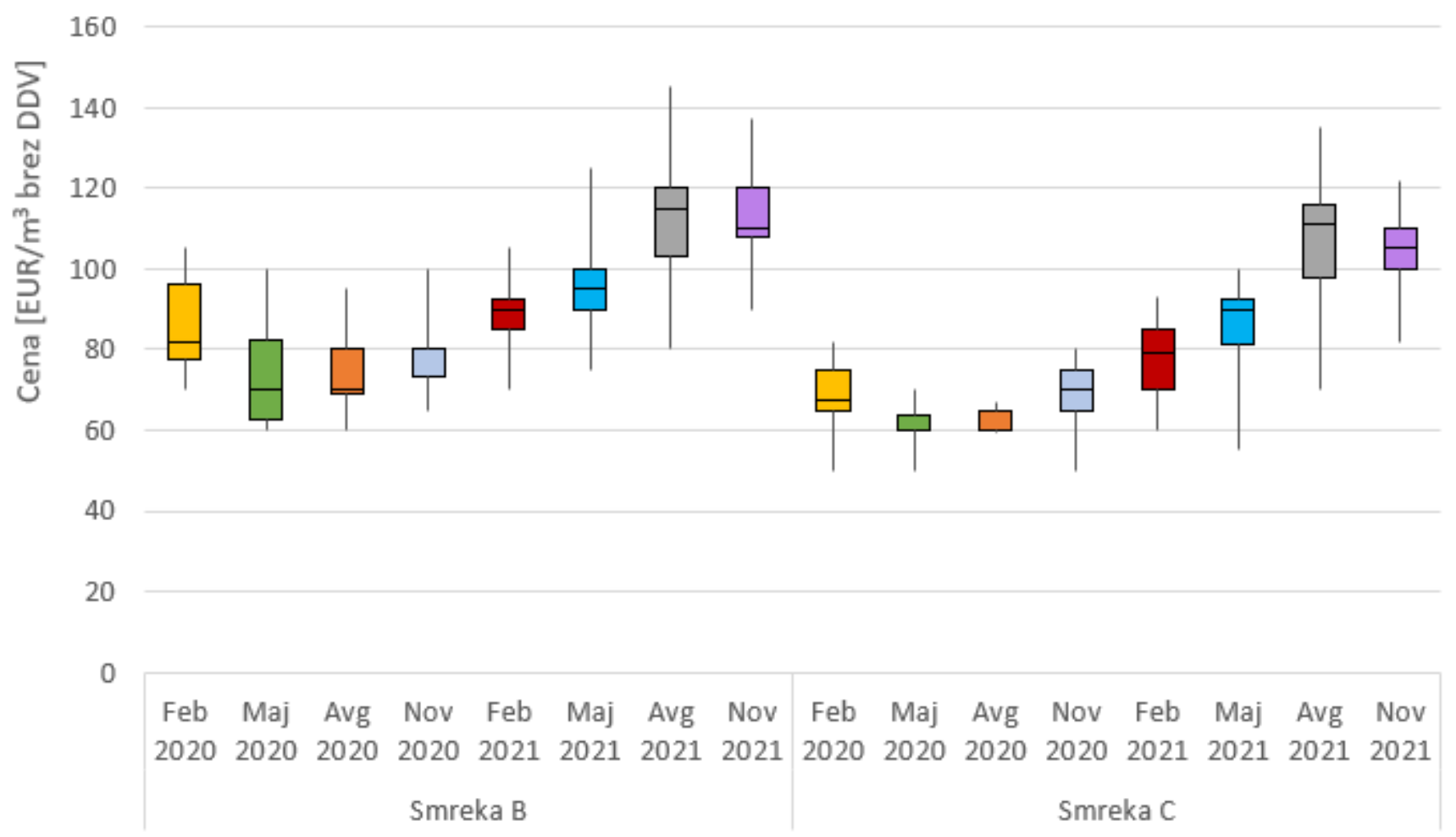

Slika 1: Prikaz razpona odkupnih cen hlodov smreke kakovostnih razredov B in C v vsakem četrtletju leta 2020 in 2021 (prečka v okviru z ročaji prikazuje srednjo vrednost - mediano, ročaji pa prikazujejo minimalno in maksimalno poročano ceno). Cene so prikazane $v € / m 3$ brez DDV na kamionski cesti.

\section{Cene hlodovine bukve visoke, za nekatere sortimente tudi rekordne v novembru lani}

Odkupne cene hlodovine bukve so bile v lanskem letu visoke, v povprečju za $6 € / m 3$ brez DDV (ali za $8 \%$ ) višje od cen v letu 2020. Najvišje cene so bile lani zabeležene v novembru in so bile za kakovostna razreda A2 in D rekordne glede na naša zbiranja cen od leta 2017 naprej. Odkupne cene hlodovine bukve kakovostnih razredov $D$ do $A 1$ so se lani v novembru gibale med $60-108 € / \mathrm{m} 3 \mathrm{brez}$ DDV, novembra 2020 pa med 55-100 €/m3 brez DDV. Največje zvišanje cen je bilo pri hlodih bukve kakovostnega razreda D2 in sicer $11 \%$. 


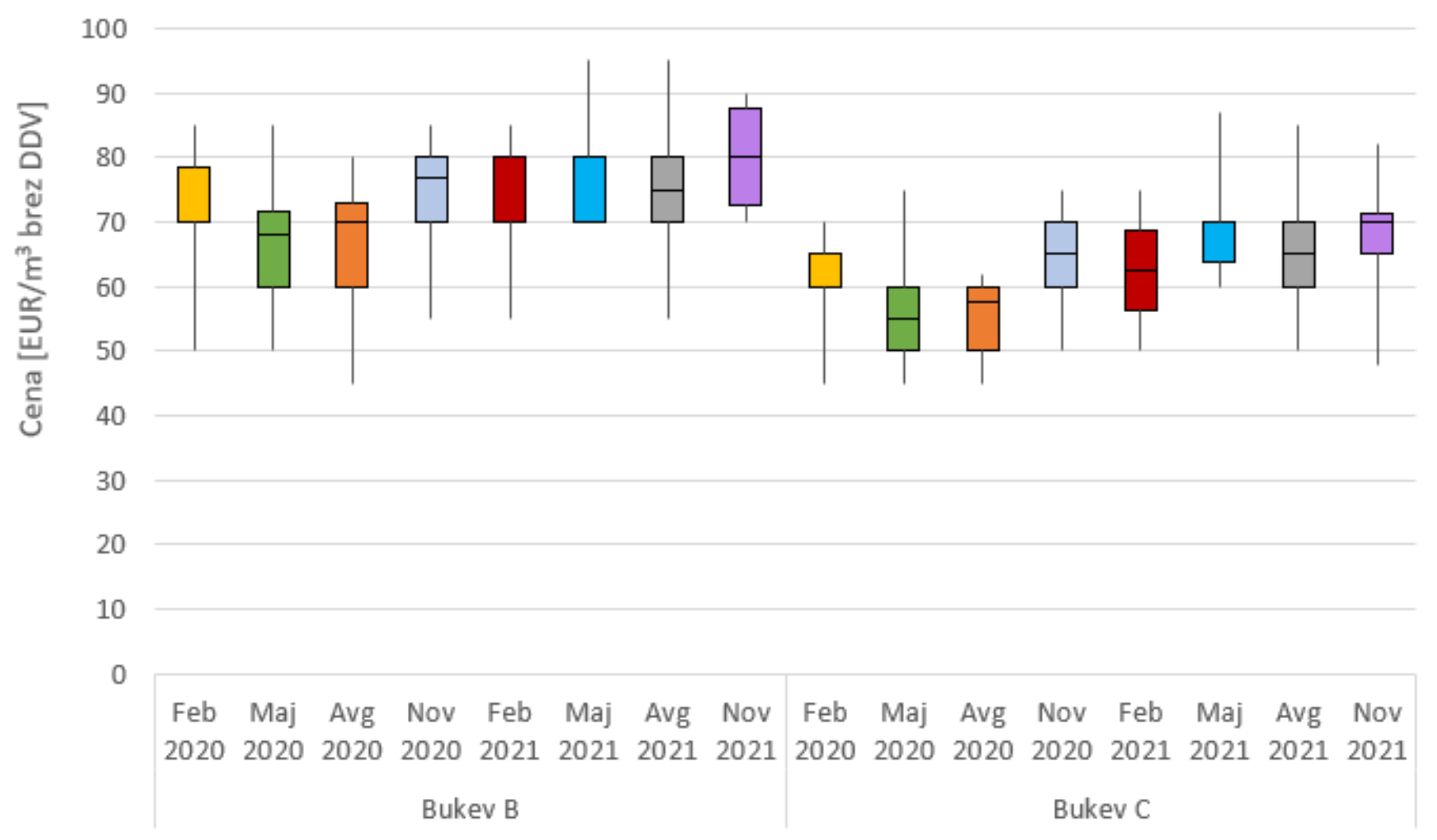

Slika 2: Prikaz razpona odkupnih cen hlodov bukve kakovostnih razredov B in C v vsakem četrtletju leta 2020 in 2021 (prečka v okviru z ročaji prikazuje srednjo vrednost - mediano, ročaji pa prikazujejo minimalno in maksimalno poročano ceno). Cene so prikazane $v € / m 3$ brez DDV na kamionski cesti.

\section{Lani so bile visoke tudi cene industrijskega okroglega lesa slabše kakovosti}

Srednja vrednost zbranih odkupnih cen lesa za celulozo in plošče smreke je v lanskem letu v povprečju znašala $26,7 € / \mathrm{m} 3$ brez DDV, medtem ko je v letu 2020 le ta znašala 24,3 €/m3 brez DDV, zelo podobno je pri jelki. Pri celuloznem lesu rdečega bora pa je srednja vrednost zbranih cen $v$ lanskem letu v povprečju znašala 25,5 €/m3 brez DDV, v letu 2020 pa 23,3 €/m3 brez DDV. Najvišje cene celuloznega lesa iglavcev so bile lani zabeležene $v$ drugi polovici leta.

Cene lesa za celulozo in plošče bukve so bile lani v avgustu in novembru visoke, srednja vrednost je v obeh mesecih znašala $48 € / \mathrm{m} 3$ brez DDV. Z izjemo obdobja november 2018-marec 2019, so bile te cene najvišje zabeležene od začetka našega zbiranja cen v letu 2017. Podobno je tudi s cenami lesa za plošče drugih trdih listavcev, pri katerem je srednja vrednost vseh zbranih cen v novembru 2021 znašala $40 € / m 3$ brez DDV, kar je največ z izjemo obdobja november 2018-marec 2019 v času našega zbiranja cen. 


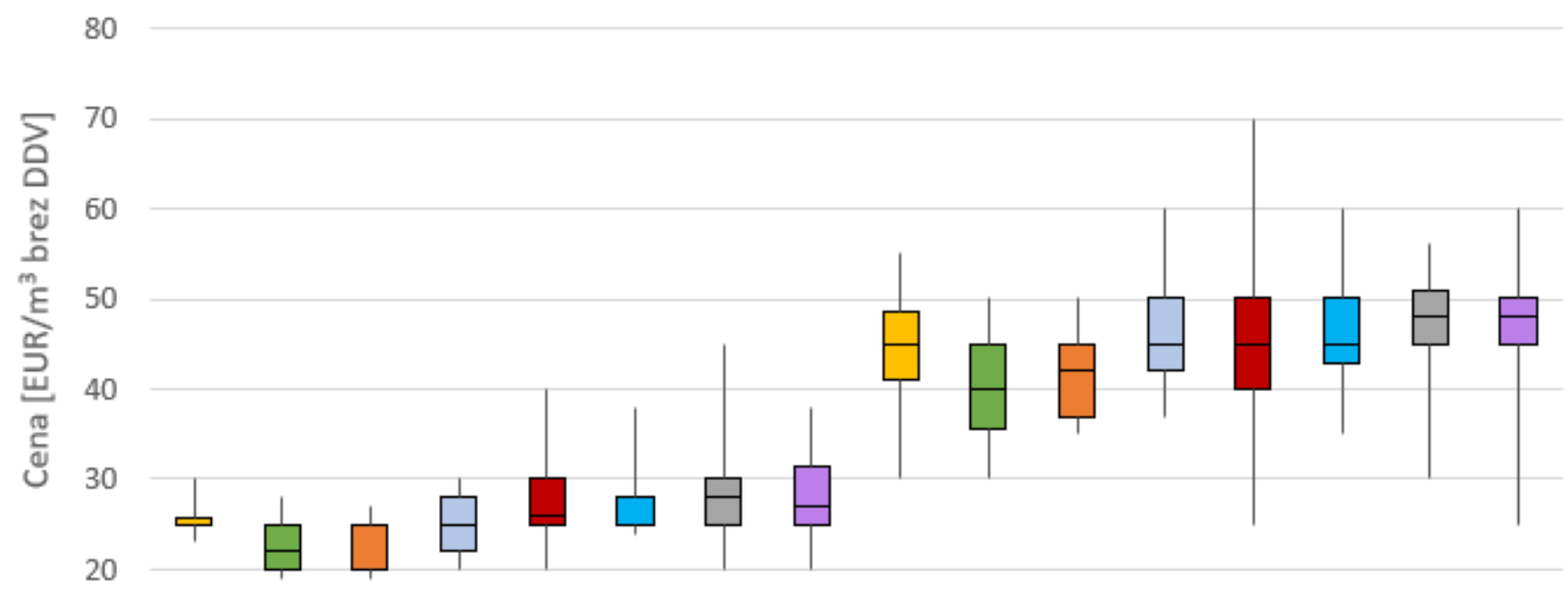

10

0

Feb Maj Avg Nov Feb Maj Avg Nov Feb Maj Avg Nov Feb Maj Avg Nov

2020202020202020202120212021202120202020202020202021202120212021

Smreka - celulozni les

Bukev - les za plošče

Slika 3: Prikaz razpona odkupnih cen lesa za celulozo in plošče smreke in bukve v vsakem četrtletju leta 2020 in 2021 (prečka v okviru z ročaji prikazuje srednjo vrednost - mediano, ročaji pa prikazujejo minimalno in maksimalno poročano ceno). Cene so prikazane $v € / m 3$ brez DDV na kamionski cesti.

\section{Cene bukovega lesa za kurjavo so od oktobra 2020 naprej na enaki ravni}

Srednja vrednost zbranih cen bukovega lesa za kurjavo je od oktobra 2020 do novembra 2021 znašala $50 € / \mathrm{m} 3$ brez DDV. Tudi pred tem je nihanje cen minimalno; na primer v letu 2020 smo zabeležili najnižjo srednjo vrednost cen $v$ aprilu in sicer $40 € / \mathrm{m} 3$ brez DDV, ko so bile zaradi zaustavitve trgovanja z GLS zaradi epidemije koronavirusa cene okroglega lesa nizke. Pri lesu za kurjavo drugih trdih listavcev so bile cene $v$ zadnjih dveh četrtletjih prejšnega leta visoke; srednja vrednost je tako znašala $45 € / \mathrm{m} 3$ brez DDV, medtem ko je v prvem četrtletju srednja vrednost znašala $40 € / \mathrm{m} 3$ brez DDV in v letu 2020 enako.

\section{Zaključki}

$\checkmark$ avgustu lanskega leta so bile cene industrijskega okroglega lesa iglavcev iz zasebnih gozdov visoke, za hlodovino prav vseh kakovostnih razredov tudi najvišje odkar na Gozdarskem inštitutu spremljamo cene okroglega lesa. Pri hlodovini smreke je bilo lani avgusta v primerjavi z avgustom 2020, opaziti največje zvišanje cen pri kakovostnih razredih C, D1 in D2, pri katerih se je cena zvišala za povprečno $76 \%$. Pri industrijskem okroglem lesu listavcev pa so bile v večini cene najvišje, za nekatere sortimente tudi rekordne v novembru lanskega leta. Porast cen sicer ni bil tako izrazit kot pri iglavcih; pri hlodovini bukve je bil novembra 2021 največji porast cen pri kakovostnih razredih A2 in D, pri katerih se je cena zvišala za povprečno $25 \%$ v primerjavi z novembrom 2020. V primeru nizkega 
obsega sanitarne sečnje, je tudi v letošnjem letu (2022) pričakovati visoke cene okroglega lesa in pa povečan uvoz iz drugih držav.

\section{Reference}

Gozdarski inštitut Slovenije (GIS). 2021. Odkupne cene gozdnih lesnih sortimentov iz zasebnih gozdov v obdobju 2017-2021. Spletni portal InfoGozd (WoodChainManager).

https://wcm.gozdis.si/sl/podatki/cene/podatki/2021100414342192/cene-gozdnih-lesnih-sortimentov/?y ear $=2021$

Jemec, T., Stare, D., Klun, J., Krajnc, N., Triplat, M., Ščap, Š., Jevšenak, J., Dolenšek, M., Piškur, M. 2017. Zasnova metodologije in vprašalnika o zbiranju cen gozdarskih storitev: odkupne cene gozdno lesnih sortimentov: strokovna ekspertiza v okviru nalog javne gozdarske službe GIS aktivnosti 5/1.1. Ljubljana: Gozdarski inštitut Slovenije, 16 str.

Stare, D., Ščap, Š. 2019. Odkupne cene gozdnih lesnih sortimentov iz zasebnih gozdov v Sloveniji = Purchase prices of the forest wood assortments from private forests in Slovenia. Gozdarski vestnik, letn. 77, št. 4, str. 170-178. 